\title{
The Effect of CSII on Armenian-Americans' Pre-purchase Information-Search Tendencies
}

\author{
Denver D’Rozario ${ }^{1} \&$ Guang Yang ${ }^{1}$ \\ ${ }^{1}$ School of Business, Howard University, Washington DC, USA \\ Correspondence: Denver D’Rozario, School of Business, Howard University, Washington DC, 20059, USA. Tel: \\ 1-301-294-6598. E-mail: ddrozario@howard.edu
}

Received: July 2, 2014 Accepted: July 17, 2014 Online Published: September 28, 2014

doi:10.5539/ijms.v6n5p52 URL: http://dx.doi.org/10.5539/ijms.v6n5p52

\begin{abstract}
Key psychometric properties of the Consumer Susceptibility to Interpersonal Influence (CSII) scale (Bearden, Netemeyer and Teel 1989) are re-assessed in a sample chosen from the Armenian-American micro-culture in the U.S.. The scale is modified in light of differences found between this group and that of the original study (Bearden, Netemeyer and Teel 1989). Differences found between these two groups are also highlighted. The effect of CSII on an Armenian-American consumer's pre-purchase external information-search tendencies are assessed in a business suit purchasing scenario. For those who are more susceptible to informational influence, family is the most important information source. For those who are more susceptible to normative influence, we find that they learn macro-cultural norms mostly from outside the family. "Neutral" and "impersonal" sources of information are found to be quite important. The theoretical and practical implications of the findings from this retailing scenario are discussed.
\end{abstract}

Keywords: CSII, Armenian-Americans, men's fashion retailing, informational influence, normative influence, impersonal influence, pre-purchase external information-search tendencies, micro-culture vs. macro-culture

\section{Introduction}

The size of micro-culture markets in the U.S. is enormous. Several are about to exceed the trillion dollar mark in purchasing power (Nielsen, 2013). The African-American market for example is estimated at over \$1 trillion annually (Nielsen, 2013). However, these markets have long been overlooked by both practitioners and academics, though that is now changing. Practitioners are beginning to devote more attention to them, given that by some projections, micro-cultures may comprise more than one-half of the U.S. population by 2050 (Passel \& Cohn, 2008). Thus for example, marketers are developing separate product lines and catalogs among others, for specific micro-culture markets. Attention from academics, however, is in need of redress.

Most of the academic marketing literature on micro-cultures has dealt with Hispanic- and African-Americans (e.g., Wallendorf \& Reilly, 1983; Wilkes \& Valencia, 1985), and while much progress has been made in understanding these two groups, not much is known about some of the smaller, but no less affluent groups (Kotkin, 1987), such as Armenian-Americans. As a result, our objectives for this study are as follows. First, we will re-calibrate the 'Consumer Susceptibility to Interpersonal Influence' (CSII) scale, originally developed using Anglo-Americans (Bearden, Netemeyer, \& Teel, 1989), in an Armenian-American sample. Second, we will examine how an Armenian-American's CSII affects his/her pre-purchase information-search tendencies across nine different information sources in a business suit purchasing scenario. Finally, theoretical and practical implications and limitations of the study will be discussed.

\section{Theoretical Background}

Susceptibility to interpersonal influence has long been recognized as a relatively stable trait that varies across individuals. Based on the early work of Deutsch and Gerard (1955) and later that of Kelman (1958), three broad subtypes of this trait have been widely recognized. The first is utilitarian influence, which operates when an individual complies with the expectations of another to gain a reward or avoid a punishment. The individual adopts a certain attitude or behavior through the process of compliance. The second is value-expressive influence, which operates when an individual accepts influence from another with whom s/he identifies. The individual adopts a certain attitude or behavior through the process of identification. The third and final type is 
informational influence, which operates when an individual accepts influence from another who is perceived as being a credible expert in some subject area. This process may take place actively, whereby the individual solicits information from this knowledgeable other, or passively, whereby s/he obtains it by the mere observation of this other. The individual adopts a certain attitude or behavior through the process of internalization because the beliefs conveyed by this credible other are congruent with the individual's value system.

Bearden, Netemeyer and Teel (1989) rigorously developeda two dimensional measure of CSII with informational (4 items) influence and normative ( 8 items) influence respectively. Their normative influence scale combines utilitarian influence and value-expressive influence from previous work into one construct. Of interest to this study is the fact that this scale too was developed on macro-culture individuals. While this rigorously-developed scale is indeed a contribution to this literature, its properties in micro-culture populations in the US are thus unclear.

As Bearden, Netemeyer and Teel (1989) themselves state, "additional tests of the scale are needed to establish its validity and final form". There is evidence to believe, however, that the properties of this scale may be different in non-Anglo-American samples. Cultural differences of this scale have been seen in samples drawn from other countries, such as China (Huang, Shi, \& Wang, 2012), India (Khare, Mishra, Parveen, \& Srivastava, 2011), and Turkey (Ebren 2009). The 'additional test' of this scale to be performed in this study is its cross-cultural validation in a micro-culture of East-European origin (namely, Armenian-Americans) that is known to stress individualistic values (Takooshian, 1986; Mirak, 1980). Mourali, Laroche and Pons (2005b) found that French Canadians are significantly more susceptible to normative influence than English Canadians, who are more individualistic. On the other hand, research shows that for public consumption of luxury brands, normative influence is found to be significant in both UK and India (Shukla, 2010).

\section{Hypotheses}

Two sets of hypotheses are proposed below. The first set deals with the effect of consumer susceptibility to informational interpersonal influence (CSIII) on an Armenian-American consumer's pre-purchase external information-search tendencies prior to the purchase of a business suit. The second set deals with the effect of consumer susceptibility to normative interpersonal influence (CSNII) on this same Armenian-American consumer's pre-purchase external information-search tendencies prior to the purchase of a business suit.

But, first, three general premises in this study must be stated. Premise one holds that micro-cultures are more susceptible to influence from the macro-culture than vice versa. The second premise is Armenian-Americans in general can be expected to be more familiar with the Anglo-American macro-culture and thus be less susceptible to informational-influence from it than would individuals from more collectivistic micro-cultures (Mourali et al., 2005). The third premise holds that Armenian-Americans would be more 'individualistic' in orientation (Hofstede, 1984) and would therefore be less susceptible to normative types of influence, in comparison with individuals from collectivistic cultures (Hofstede, 1984).

Finally, for validation in a consumption context, pre-purchase external information-search tendencies was chosen, given that Hirschman (1983) found significant differences in the pre-purchase information-search patterns, across the four European-American groups.

To ensure that both CSIII and CSNII would be heightened in our study participants, we needed to present to subjects a product purchase scenario that implied an increased susceptibility to both types of interpersonal influence when the product is purchased or used. As we describe in a subsequent section, we chose the purchase of a business suit for an upcoming job interview for the following three reasons. First, a business suit is used in 'public', as per Bearden and Etzel's (1982) typology. Second, this is a product to which much symbolic meaning is attached (Midgley, 1983). For both of these reasons, purchasers of a business suit would be especially susceptible to normative interpersonal influence. A third and final reason for the choice of the business suit was because it is a product which most people would consider a significant purchase, in terms of its price. This would therefore necessitate a significant amount of informational input prior to its purchase, thereby rendering its purchasers susceptible to informational interpersonal influence.

Because the CSII scale measures a person's susceptibility to inter-personal influence, we expect that this scale will not pick up on any relationship with impersonal information sources, such as In-store displays (F), Advertisements $(\mathbf{G})$ and Fashion books and guides $(\mathbf{H})$.

Further, because of the 'luxury' consumption effect, we expect that a person's CSIII would be heightened, regardless of ethnicity and so such a person could be expected to solicit information from a wide variety of personal sources, both within and outside the family. Further, as per Park and Lessig (1977), those most 
susceptible to informational-interpersonal influence could be expected to both: (a) overtly seek information from personal, non-commercial sources (such as family, friends and coworkers) and personal, commercial sources (such as in-store salespersons), and/or (b) passively seek information from observational personal sources (such as what business suits other people wear), whereas those least susceptible to this type of influence could be expected to rely on themselves. Thus,

H1: Individuals most susceptible to informational interpersonal influence would be, most likely to consult personal sources both inside and outside the family, specifically,
A: family,
B: friends,
C: co-workers,
D: salespersons, and,

E: the mere observation of what other people wear,

and they would not be likely to consult impersonal sources, specifically,

F: in-store displays,

G: advertisements, and

H: fashion books and guides.

On the other hand, those least susceptible to this influence-type would be most likely to,

I: rely on themselves.

Because of the cultural-similarity of Armenian- and Anglo-Americans that stresses the importance of individualism, we expect Armenian-Americans who are more susceptible to normative interpersonal influence to seek information about this product primarily from sources outside their family. Thus,

H2: Individuals most susceptible to normative interpersonal-influence would be,

most likely to consult personal sources outside the family, specifically,

B: friends,

C: co-workers,

D: salespeople, and,

E: the mere observation of what other people use,

and they would not be likely to consult, personal sources, inside the family, thus,

A: family,

and they would also not be likely to consult impersonal sources, specifically,

F: in-store displays,

G: advertisements, and

H: fashion books and guides.

On the other hand, those least susceptible to this influence-type would be most likely to,

I: rely on themselves.

For ease of reading and discussion, we again list these hypotheses in Table 2.

\section{Method}

\subsection{Population}

As stated at the outset, the Armenian-American micro-culture is the focus of this study. The rationale for its choice is as follows. Armenian immigrants were chosen for the following two reasons. First, the bulk of their population has arrived in the U.S. quite recently and hence comprise many first-generation immigrants that can be sampled for this study (Mirak, 1980). Second, Armenians are known to stress individualistic values (Talai, 1986) and were thus expected to be less susceptible to normative interpersonal influence (Mourali et al., 2005).

\subsection{Instrument}

This study was part of a larger survey of several micro-cultures in the U.S.. Towards this end, the CSII scale 
(Bearden, Netemeyer, \& Teel, 1989) was included, along with a number of other lifestyle, demographic and consumption-related questions, in the original survey instrument. Some of these other questions will be referred to in subsequent sections, where some are used to revalidate the CSII scale and others to assess the demographic statuses of the various sub-samples chosen in the micro-culture of interest in this study. Of the many consumption-related questions asked, the following was specifically chosen, to test for consistency with the findings of Hirschman (1983), discussed earlier.

Imagine that you were going to be interviewed for a job and were trying to decide what clothing to buy to wear at the interview. Please rate the following sources, in terms of how likely you would be to use each of them for information in deciding what clothing to wear at this interview.

The potential sources listed (from Newman (1977) and Beatty and Smith (1987)) were: (a) family, (b) friends, (c) co-workers, (d) salespeople in clothing stores, (e) observation of other people, (f) in-store displays, (g) advertisements, (h) fashion books/guides, (i) self and (j) other. On a scale from 1 to 4, for each source, respondents were to indicate if they would: (1) "definitely not", or (2) be "highly unlikely", or (3) be "somewhat likely", or (4) be "highly likely" to consult it, prior to the purchase in question.

\subsection{Translation}

The questionnaire, first generated in English, was translated, using the back-translation technique of Brislin (1970). First, a professional Armenian translator rendered the English version in Armenian. Second, two bilingual Armenian students translated it back into English. Discrepancies between the two back-translated versions were resolved only after all four raters (i.e., two Armenian students, an Armenian-language expert and the first author of this paper) had agreed on an unambiguous restatement of the original question. The questionnaire was then tested on 30 Armenian students studying at a major northeastern university. Feedback from this group revealed no misunderstandings.

\subsection{Sample}

In the Spring of 1990, an independent sub-sample was drawn from each of three sampling frames of Armenian-Americans in the U.S. We knew a-priori (from Lai 1980; Mirak 1980) that within this micro-culture, individuals from sub-sample \# 1 would be comprised of more recent arrivals in the U.S., in comparison with individuals from sub-sample \# 2, who in turn would be comprised of more recent arrivals, in comparison with individuals from sub-sample \# 3. We needed this variation in time spent in the US, because we expected that individuals would become less susceptible to interpersonal influence from the host-culture, the more time they spent in it.

For the first sub-sample, two questionnaires were mailed out to each of 500 households living all over the New York Metropolitan area who were: (a) recent arrivals in the U.S. from the Armenian diaspora (Takooshian 1986), and (b) were being assisted at the time by the major ethnic social-service organization in this micro-culture (who provided this study with the list of these household addresses). A total of 313 questionnaires were returned, for a response rate of $31.3 \%$.

The second sub-sample was drawn from this micro-culture by randomly picking 300 "Armenian" names from telephone books of Queens and Manhattan, in NYC. Two questionnaires were mailed out to each of these households. A hundred and seven questionnaires were returned, for a response rate of $17.83 \%$.

For the third sub-sample, in the Spring of 1994, 2 questionnaires were mailed out to each of 300 households, with "Armenian" last names, in affluent, non-ethnic neighborhoods all over Long Island, NY. Eighty three questionnaires were returned in all, for a response rate of $13.83 \%$.

\section{Results}

\subsection{Validity}

\subsubsection{Cross-Validity}

To check for cross-validity (Jacoby 1978), the sub-samples were compared on their scores for both sub-scales. As expected, on both informational- and normative-influence, the Long-Island sub-sample was less susceptible than the telephone-book-based Manhattan and Queens sub-sample, which in turn was less susceptible than the ethnic-organization-list-based Manhattan and Queens sub-sample. All these differences were significant at the $p<.01$ level.

\subsubsection{Construct-Validity}

To check for convergent validity, a confirmatory factor analysis was performed on the eleven items retained 
from the earlier exploratory factor analysis. For a two-factor correlated structure, the GFI and AGFI were 0.95 and 0.92 respectively. The signs on all the $\Lambda_{\mathrm{x}}$ parameters were in the direction expected and all the indicator $t$-values were highly significant $(p<.01)$.

To check for discriminant validity, first, the assumption of the underlying two-factor structure was checked, by testing an alternate one-factor model. It however produced a worse fit to the data, with a GFI and AGFI of 0.87 and 0.80 respectively. Second, the 0.01 confidence interval for the correlation between the informational- and normative-influence factors (i.e., $\varphi_{21}$ ) did not include the value 1 , indicating that the two factors though correlated are nonetheless distinct. Finally, as per Fornell and Larcker (1981), the average variance-extracted estimate for the normative- and informational-influence construct-pair of 0.45 , was greater than the variance shared by this construct-pair, of 0.21 . Thus, it can be said that the two constructs, though related, are nonetheless distinct from one another, a result consistent with the findings of Bearden, Netemeyer and Teel (1989). Additionally, estimates of construct reliability for the informational- and normative-influence factors were $74 \%$ and $85 \%$ respectively.

Table 1. Armenian micro-culture-sample statistics

\begin{tabular}{lllllllll}
\hline Micro-culture & No. of & & Range & Mean & SD & Reliability & Variance \\
\cline { 2 - 6 } (Construct) & items & & & & Alpha & Construct & Retest & extracted \\
(Informational) & 3 & $3-21$ & 11.83 & 4.63 & 0.74 & 0.74 & --- & 0.48 \\
(Normative) & 8 & $8-56$ & 15.80 & 8.64 & 0.84 & 0.85 & --- & 0.42 \\
\hline
\end{tabular}

Note. For ease of comparison, this table was set up to be identical to Table 1, page 477 (Bearden, Netemeyer and Teel 1989).

\subsection{Regression Results}

To test the two sets of information-search hypotheses, each of the two respondent scores for CSIII and CSNII were made the dependent variable in a regression analysis in which their self-reported tendencies to consult nine sources of information (discussed earlier), were made the independent variables, after controlling for respondent age, income and education. The standardized $\boldsymbol{\beta}$ coefficients from each of these two regression analyses are shown in two separate columns in Table 2.

As expected, those most susceptible to informational influence consulted their family (H1A, $p<0.01)$, friends (H1B,$p<0.01)$, co-workers (H1C, $p<0.05)$ and observed what other people wore (H1E, $p<0.10)$. However, the influence of the in-store salesperson was not significant (H1D, ns), contrary to expectations. Those least susceptible to this influence type relied solely on themselves, as expected, however, this relationship was not significant (H1I, ns).

Also as expected, no significant relationship was seen between informational interpersonal influence and Advertisements (H1G, ns) and Fashion books and guides (H1H, ns). However, the influence of the In-store displays was significant (H1D, $\mathrm{p}<0.10)$, contrary to expectations.

Finally, based on the magnitude of the standardized $\beta$ coefficients, we see that the rank-order influence of the various information sources was as follows: family was most important $(\boldsymbol{\beta}=0.26)$, followed by friends $(\boldsymbol{\beta}=0.21)$, and then co-workers $(\boldsymbol{\beta}=0.13)$, while observation of other people $(\boldsymbol{\beta}=0.10)$, and in-store displays $(\boldsymbol{\beta}=0.10)$, tied for fourth place. We discuss the significance of all these findings in the next section.

As expected, those most susceptible to normative interpersonal influence did not consult their family to any significant degree (H2A, ns). However, they did consult a variety of other sources outside of the family.

Among the expected, significant positive relationships were the following. Those most susceptible to normative interpersonal influence consulted friends (H2B, p $<0.01)$, co-workers $(\mathbf{H 2 C}, \mathrm{p}<0.01)$, in-store-salesperson (H2D, $\mathrm{p}<0.01)$, and observed what other people wore $($ H2E, $\mathrm{p}<0.01)$.

Those least susceptible to normative influence type relied solely on themselves, as expected (H1I, $p<0.01)$.

However, contrary to expectations, significant positive relationships were found for the following sources. Those most susceptible to normative interpersonal influence consulted in-store displays $(\mathbf{H} 2 \mathbf{F}, \mathrm{p}<0.01)$, advertisements $(\mathbf{H} 2 \mathrm{G}, \mathrm{p}<0.01)$ and fashion books and guides $(\mathbf{H} 2 \mathrm{H}, \mathrm{p}<0.01)$.

Finally, based on the magnitude of the standardized $\boldsymbol{\beta}$ coefficients, we see that the rank-order influence of the various information sources was as follows: in-store salesperson $(\boldsymbol{\beta}=0.29)$ was most important, followed by the observation of what other people wore $(\boldsymbol{\beta}=0.24)$, in-store displays $(\boldsymbol{\beta}=0.23)$, co-workers $(\boldsymbol{\beta}=0.20)$, friends 
$(\boldsymbol{\beta}=0.19)$, advertisements $(\boldsymbol{\beta}=0.18)$ and fashion books and guides $(\boldsymbol{\beta}=0.17)$.

We discuss the significance of all these findings in the next section.

Table 2. Business suit purchase scenario

\begin{tabular}{lll}
\hline Information-Search Sources & \multicolumn{2}{l}{ Type of Susceptibility to Interpersonal Influence } \\
\cline { 2 - 3 } (listed in order, as in the questionnaire) & Informational & Normative \\
\hline A. Consult family (and relatives) & H1A: $0.26^{\mathrm{a}}$ & H2A: 0.07 \\
B. Consult friends & H1B: $0.21^{\mathrm{a}}$ & H2B: $0.19^{\mathrm{a}}$ \\
C. Consult business associates/coworkers & H1C: $0.13^{\mathrm{b}}$ & H2C: $0.20^{\mathrm{a}}$ \\
D. Consult Salesperson (in clothing store) & H1D: 0.04 & H2D: $0.29^{\mathrm{a}}$ \\
E. Observation of other people & H1E: $0.10^{\mathrm{c}}$ & H2E: $0.24^{\mathrm{a}}$ \\
F. In-store Displays & H1F: $0.10^{\mathrm{c}}$ & H2F: $0.23^{\mathrm{a}}$ \\
H. Neutral Sources (e.g., Fashion Books) & H1H: 0.05 & H2H: $0.17^{\mathrm{a}}$ \\
I. Rely on self & H1I: 0.04 & H2I: $-0.17^{\mathrm{a}}$ \\
\hline
\end{tabular}

Note. The $\beta$ coefficient in each cell was obtained after controlling for respondent age, income and education. Significance of coefficients are indicated in accompanying superscripts, as follows: $\mathrm{a}-\mathrm{p}<.01, \mathrm{~b}-\mathrm{p}<.05, \mathrm{c}-\mathrm{p}<.10$. For ease of reading, in each row, shaded cells indicate $\beta$ coefficients that are significant at least at the .10 level.

\section{Discussion}

A systematic examination of the effect of the CSII trait on a key consumer-behavior construct, namely, pre-purchase external information search tendencies revealed several expected results and some unexpected results as well. Both classes of findings (i.e., the expected and the unexpected) are instructive in their own right. We discuss these two types of findings next.

We begin by discussing the expected results. First, as expected, for a mostly first-generation (Armenian-American) immigrant population and especially for the product purchase in question (i.e., business suits) the (immigrant) individual is most susceptible to normative interpersonal influence from sources outside his/her immediate family. That is why H2A was not significant. In other words, immigrants learn the macro-culture's 'norms' (e.g, what is 'appropriate' to wear to a job interview), mostly from sources outside the family.

Second, since the CSII scale measures susceptibility to interpersonal influence, four of the six listed personal sources were significantly related to CSIII and five of these sources were significantly related to CSNII. Three of these significant sources were the same for CSIII and CSNII. They were friends (B), co-workers (C) and the observation of what other people wore (E). Apparently these three sources provide both 'information' and 'norms' to immigrant consumers. Further, all three sources are outside the family and are 'neutral' sources of information (i.e., they are not under the control of marketers).

The differences between how CSIII and CSNII relate to personal sources of information arises in the remaining significant sources and they offer us new insight into how these two types of CSII operate. Of all the nine sources of information examined family had the highest $\boldsymbol{\beta}$ coefficient (significant at $p<0.01$ ) for CSIII, but it was not significantly related to CSNII. So apparently, an (Armenian-American) immigrant's family is the most important source of 'information' when it comes to the purchase of a business suit. However, this same source is completely ineffective (that is why it is insignificant) when it comes to providing the same (Armenian-American) immigrant with 'norms' on what to purchase. This makes perfect sense, because the 'norms' (e.g., what styles and colors are 'in') that dictate what formal clothing to buy to wear for an upcoming job interview (in the macro-culture) would logically have to come from sources in the macro-culture and this would logically therefore be outside the immigrant's family. On the other hand, the important 'information' that the immigrant's family might provide him/her to guide this suit purchase might be what 'fits' him best, etc. This is however speculative on our part, because the specific information that could be sought by the (immigrant) consumer in this purchase scenario was not ascertained in this study and this remains an avenue of future investigation.

A further difference between how CSIII and CSNII relate to personal sources of information arises in the two additional sources that relate significantly to CSNII. The first of these two additional significant personal sources is the salesperson in the (clothing) store. Interestingly, it is also the most important (i.e., it had the highest $\boldsymbol{\beta}$ coefficient of all nine sources for CSNII). So, it appears that for an (Armenian-American) immigrant consumer looking to purchase a business suit for an upcoming job interview, the most important source of 'norms' to 
follow in deciding what is the most 'appropriate' suit to purchase comes from the salesperson in the clothing store. Interestingly, this same source is completely ineffective when it comes to providing the same (Armenian-American) immigrant with 'information' on what to purchase (that is why H1D was not significant). It could well be that the (Armenian-American) immigrant consumer asks the salesperson in the clothing store what styles, colors, fabrics, etc are 'in' and what are 'out' (i.e., the prevailing macro-culture 'norms') and once $\mathrm{s} / \mathrm{he}$ decides on what to purchase within these norms, the salesperson is replaced by the family (as discussed above) as the source to 'go to' for advice on what 'fits' him/her best, what price range to buy from, etc. As discussed above, this is speculative on our part, because the specific information that could be sought by the (immigrant) consumer in this purchase scenario was not ascertained in this study and this remains an avenue of future investigation.

The second of these two additional significant personal sources is 'Self'. As expected, those individuals who are less susceptible to normative interpersonal influence rely on themselves. This makes perfect sense, because an individual who knows what the 'norms' are for any situation is logically unlikely to ask anyone about what these norms are because s/he knows it already. This is exactly what happens in the case of an Armenian-American immigrant consumer who knows the 'norms' that guide the purchase of a business suit. S/he asks nobody and instead relies on his/her own prior acquired knowledge. What is however surprising and still remains a mystery to us (at this point) is why this same explanation does not apply to H1I. As can be seen (from table 2), the $\boldsymbol{\beta}$ coefficient for $\mathbf{H 1 I}$ is 0.04 , which is neither negative (as we expected) nor significant (as we expected). This (i.e., H1I) therefore remains an avenue of future investigation.

The final set of expected results pertain to the (mostly) non-significant relationships between CSIII and the impersonal sources of information that we investigated in this study. Two of the three impersonal sources that we investigated in this study, namely, advertisements and fashion books and guides were not significantly related to CSIII. That does not mean that these two sources are unimportant inputs to decision-making for an (Armenian-American) immigrant's purchase of a business suit. All that these two non-significant results tell us is that since CSIII is a sub-scale that measures a person's susceptibility to informational interpersonal influence it may not pick up their (possible) susceptibility to impersonal influence from these two sources. This is more an issue of how CSII was originally conceived (as a measure of interpersonal influence) and less an issue of whether these two (impersonal) sources might be important inputs to decision-making for business suit purchases. It however remains an avenue of future investigation insofar as we might need to develop a measure of susceptibility to impersonal influence that could complement CSII in more comprehensive future investigations of susceptibility to all types of influence (i.e, personal and impersonal).

Now, for the unexpected results, here are the more important among them. First, contrary to expectations, all three impersonal sources that we investigated in this study, namely, in-store-displays, advertisements and fashion books and guides were significantly related to CSNII. As discussed above, we did not expect a measure of susceptibility to normative interpersonal influence to pick up any significant susceptibility to impersonal influence from these three sources, but it did. One possible, but less likely explanation is 'methods' bias. Briefly, a skeptic of our results might say that we obtained these three significant results because these three (impersonal) sources were listed right in between six other personal sources of information. So, the skeptic might say that the respondent could have been (inadvertently and subconsciously) responding to all nine sources as if they were all 'personal' sources. This is indeed a 'rival hypothesis' to what we have proposed in our hypotheses H2F, H2G and $\mathrm{H} 2 \mathrm{H}$ (i.e., non-significant relationships). However, this rival hypothesis (i.e., of 'methods bias') does not hold up for H1G and H1H. In other words, if the respondent inadvertently and subconsciously responded to all three impersonal sources, as if they were personal sources, why is CSIII not picking up a significant relationship with two of these three sources (i.e., advertisements (non-significant H1G) and fashion books and guides (non-significant H1H). We discuss this in at some more length in our limitations section.

A more plausible explanation (at least to us) is that in-store-displays (H1F), advertisements (H1G) and fashion books and guides $(\mathbf{H 1 H})$ are all significant sources from which 'norms' are picked up by (Armenian-American) immigrant consumers, at least for the case of business suit purchases. Thus, even though a measure of an individual's susceptibility to normative influence is conceived to only pick up this susceptibility to personal sources of this normative influence, it still might pick up 'shared variance' with susceptibility to normative impersonal influence, because for an immigrant 'norms' and therefore normative influence might be a much bigger influence in their lives (as they interact with the macro-culture) than 'information' and 'informative influence'. In contrast, as discussed earlier (for H1A), the most significant source of 'information' that guides product purchases (at least for business suits) appears to come from family and not from outside sources (personal or impersonal). In other words, susceptibility to normative and informational influence might be driven 
by different sets of factors that are significantly different that they warrant a separate re-investigation (of susceptibility to personal and impersonal influence) in the future. This too remains an avenue of future investigation.

Finally, for CSIII, in-store displays (H1F) were an unexpectedly significant source of 'information' for business suit purchases, in contrast to advertisements (H1G) and fashion books and guides $(\mathbf{H 1 H})$, which as discussed previously, were non-significant. We also wish to point out that for CSNII, within the three (significant) impersonal sources, in-store displays were the most significant $(\boldsymbol{\beta}=0.23)$, followed by advertisements $(\boldsymbol{\beta}=0.18)$, followed by fashion books and guides $(\boldsymbol{\beta}=0.17)$. Thus, we note that for both CSIII and CSNII, in-store displays figure prominently as a significant provider of 'information' and 'norms' respectively. We also note the heightened importance of in-store displays that Seock and Bailey (2009) found for Hispanic consumers in their apparel shopping behavior.

We are unsure (at this point) why in-store displays are differentially significant and therefore at this point, we are curious as to what might be driving this apparently idiosyncratic significance. It may have something to do with the nature of 'information' that in-store displays convey (e.g., to touch, feel and 'try out' clothing) which makes them more unique and unduplicated sources of information that advertisements (because of a possible perception of 'source bias') and fashion books and guides (because they merely portray and describe clothing, rather than allow the consumer to actually interact with them, as in the case of in-store displays) lack. This is however merely speculative (on our part) at this point, but it nonetheless can serve as starting point for future investigations of these impersonal sources of information.

\section{Implications}

\subsection{Theoretical}

We have now re-validated Bearden, Netemeyer and Teel's (1989) 'Consumer Susceptibility to Interpersonal Influence' (CSII) scale in a population that is different (i.e., Armenian-Americans) from that in which it was originally developed (i.e., Anglo-Americans). We have also shown in this study how CSII relates to a key aspect of consumption-related behavior, namely pre-purchase external information search behavior.

An additional, unexpected finding that we have gotten from this re-validation study is that we have learned that CSII at the least has some additional valuable properties (i.e., it also relates to impersonal sources of influence) and at best, we may have learned that CSII measures only one-half of the puzzle of how consumers are influenced. It appears that the other half of this puzzle of consumer influence comes from impersonal sources, such as in-store displays, advertisements and neutral sources (such as fashion book and guides, Consumer Reports, or online sources, etc.). As a result, we just might have to develop a complementary measure to CSII, called 'Consumer Susceptibility to Impersonal Influence'. This remains an avenue of future investigation.

\subsection{Practical}

We know from this study that CSIII and CSNII relate to (and possibly are driven by) very different sources of information. CSIII seems to be driven (at least for Armenian-Americans) primarily by sources within the family. CSNII on the other hand seems to be driven (at least for Armenian-Americans) primarily by sources outside the family.

In addition, CSIII appears to be linked to sources of information that (with the exception of in-store displays) are not marketer-controlled. CSNII on the other hand appears to be linked to sources of information that include all three marketer-controlled sources that we investigated (i.e., in-store displays, advertisements and in-store salesperson). Further and perhaps most surprising of all, one of these marketer-controlled sources (i.e., the in-store salesperson) was the most significantly related to CSNII. We know that for the learning of 'value-expressive behavior', adolescents are socialized primarily by the mass-media (Moschis and Churchill 1978) and acculturation (Jamal and Shukor 2014). For Armenian-American consumers on the other hand, it appears that this socialization might take place (at least for business suit purchases) primarily through the in-store salesperson.

Based on just these findings we can begin to see that the two sub-scales of CSII, namely CSIII and CSNII may now be differentially used to influence Armenian-American purchases (at least for business suits) in the U.S. and possibly other populations as well (Mourali, Laroche, \& Pons 2005a). For example, purveyors of fashion and clothing to this (Armenian-American) population group can target the in-store salespeople (with information on new styles, colors, fabrics, etc.), as the primary opinion-leaders to influence Armenian-American consumers of fashion and clothing products. On the other hand, the primary purchaser's family may also be targeted, via a separate campaign (e.g., through advertising or online social media) that provides different types of information 
(e.g., the affordability of different price ranges) to the primary purchaser from what the in-store salesperson may provide (e.g., styles, fabrics, colors). For pure online clothing stores, the online pictures or videos that show 3D of apparel on models are equivalent to in-store displays, which can be important source of influence pre-purchase. The online version of an in store salesperson would be a real-time online chat option that certain online stores provide as an option to assist sales. It appears from this study that clothing online stores would benefit from having this option provided to the consumer for assistance.

\section{Limitations}

The first limitation was our use of non-probability samples, which while consistent with the intervention falsification (i.e., scale re-validation) goals of this study, nonetheless remains a threat to the external validity (Calder, Phillips and Tybout 1982) of the re-validated scale. The re-testing of this scale with representative samples of Armenian-Americans, as well as others, thus remains an avenue of future investigation.

A second limitation was our use of self-administered questionnaires only. Other methods of administering this scale, such as the personal interview, were thus not tested. The extent of methods-bias was thus not ascertained in this study. Neither was it in that of the original scale developer's (Bearden, Netemeyer and Teel 1989). While beyond the scope of this study, the use of multiple methods to measure this scale thus also remains an avenue of future investigation.

A third limitation was our use of self-reports, rather than observational measures of information-search, as suggested by Newman and Lockeman (1975). However, this is not a problem for two reasons. First, we did not use a recall measure of a past purchase, which was criticized by Newman and Locekman (1975). Rather, we used a hypothetical purchase scenario, to ascertain search tendencies, for which self-report measures may not be inappropriate (Newman 1977). Second, the purpose of this study anyway was to re-validate an existing scale, rather than test theories of information-search. Future research could retest these scales using other measures of information-search or entirely different consumer-behavior constructs.

A final limitation was the possibility (as we discussed earlier) that we may have inadvertently introduced 'methods bias' into the information search portion of our questionnaire by listing three impersonal sources of information (i.e., in-store displays, advertisements and fashion books/guides) along with six other sources of (personal) information. That is, we may have inadvertently caused the respondent to 'respond' to these three impersonal sources with the same 'frame of mind' as s/he may have done when responding to the six personal sources. As we also discussed earlier, this possibility seems less likely when we looks at the non-significant relationships between two of these three sources (i.e., advertisements and fashion books/guides) and CSIII. To avoid being repetitious, we also advanced a more likely explanation for these anomalous results in the previous section. We nonetheless must remain open to addressing this (methods bias) limitation if our alternative explanation (of different forces driving CSIII and CSNII) does not pan out in future investigations.

\section{References}

Bearden, W. O., \& Etzel, M. J. (1982). Reference Group Influence on Product and Brand Purchase Decisions. Journal of Consumer Research, 9(September), 183-194. http://dx.doi.org/10.1086/208911

Bearden, W. O., Netemeyer, R. G., \& Teel, J. E. (1989). Measurement of Consumer Susceptibility to Interpersonal Influence. Journal of ConsumerResearch, 15(March), 473-481. http://dx.doi.org/10.1086/209186

Beatty, S. E., \& Smith, S. M. (1987). External search effort: An investigation across several product categories. Journal of Consumer Research, 83-95. http://dx.doi.org/10.1086/209095

Brislin, R. W. (1970). Back-Translation for Cross-Cultural Research. Journal of Cross-Cultural Psychology, I(September), 185-216. http://dx.doi.org/10.1177/135910457000100301

Calder, B. J., Phillips, L. W., \& Tybout, A. M. (1982). The concept of external validity. Journal of Consumer Research, 240-244. http://dx.doi.org/10.1086/208920

Deutsch, M., \& Gerard, H. B. (1955). A Study of Normative and Informational Influence Upon Individual Judgement. Journal of Abnormal and Social Psychology, 51(November), 629-636. http://dx.doi.org/10.1037/h0046408

Ebren, F. (2009). Susceptibility to interpersonal influence: A study in Turkey. Social Behavior and Personality: an International Journal, 37(8), 1051-1063. http://dx.doi.org/10.2224/sbp.2009.37.8.1051

Fornell, C., \& Larcker, D. F. (1981). Structural equation models with unobservable variables and measurement error: Algebra and statistics. Journal of Marketing Research, 382-388. http://dx.doi.org/10.2307/3150980 
Hirschman, E. C. (1983). Cognitive Structure across Consumer Ethnic Subcultures: A Comparative Analysis. In R. P. Bagozzi \& A. M. Tybout (Eds.), Advances in Consumer Research (pp. 197-202).

Hofstede, G. (1984). Culture's Consequences: International Differences in Work-related Values. Beverly Hills, CA: Sage Publications.

Huang, Y., Shi, J., \& Wang, L. (2012). Consumer susceptibility to interpersonal influence in Mainland China. Asian Journal of Social Psychology, 15(2), 140-144. http://dx.doi.org/10.1111/j.1467-839X.2011.01365.x

Jacoby, J. (1978). Consumer Research: How Valid and Useful Are All Our Consumer Behavior Research Findings? - A State of the Art Review. Journal of Marketing, 42(April), 87-96. http://dx.doi.org/10.2307/1249890

Jamal, A., \& Shukor, S. A. (2014). Antecedents and outcomes of interpersonal influences and the role of acculturation: The case of young British-Muslims. Journal of Business Research, 67(3), 237-245. http://dx.doi.org/10.1016/j.jbusres.2013.05.009

Jones, E. E., \& Gerard, H. B. (1967). Social Psychology. New York: John Wiley and Sons, Inc.

Kelman, H. C. (1958). Compliance, Identification and Internalization: Three Processes of Attitude Change. Journal of Conflict Resolution, 2(1), 51-60. http://dx.doi.org/10.1177/002200275800200106

Khare, A., Mishra, A., Parveen, C., \& Srivastava, R. (2011). Influence of consumers' susceptibility to interpersonal influence, collective self-esteem and age on fashion clothing involvement: A study on Indian consumers. Journal of Targeting, Measurement and Analysis for Marketing, 19(3), 227-242. http://dx.doi.org/10.1057/jt.2011.22

Kotkin, J. (1987). Selling to the New America. Inc, 9(8), 44-47, 50 \& 52.

McGuire, W. J. (1968). Personality and Susceptibility to Social Influence. In E. F. Borgatta \& W. W. Lambert (Eds.), Handbook of Personality Theory and Research (pp. 1130-1187). Chicago: Rand McNally.

Mirak, R. (1980). Armenians. In S. Thernstrom (Ed.), Harvard Encyclopedia of American ethnic groups. Cambridge, Massachusetts: Harvard University Press.

Moschis, G. P. (1976). Social Comparison and Informal Group Influence. Journal of Marketing Research, 13(August), 237-244. http://dx.doi.org/10.2307/3150733

Moschis, G. P., \& Churchill, G. A. (1978). Consumer Socialization: A Theoretical and Empirical Analysis. Journal of Marketing Research, 15(November), 599-609. http://dx.doi.org/10.2307/3150629

Mourali, M., Laroche, M., \& Pons, F. (2005a). Antecedents of consumer relative preference for interpersonal information sources in pre-purchase search. Journal of Consumer Behaviour, 4(5), 307-318. http://dx.doi.org/10.1002/cb.16

Mourali, M., Laroche, M., \& Pons, F. (2005b). Individualistic orientation and consumer susceptibility to interpersonal influence.Journal of Services Marketing, 19(3), 164-173. http://dx.doi.org/10.1108/08876040510596849

Newman, J. W. (1977). Consumer External Search: Amount and Determinants. In A. G. Woodside, J. N. Sheth, \& P. D. Bennett (Eds.), Consumer and Industrial Buying Behavior. New York, NY: North-Holland.

Newman, J. W., \& Lockeman, B. D. (1975). Measuring Pre-purchase Information Seeking. Journal of Consumer Research, 2(December), 216-222. http://dx.doi.org/10.1086/208634

Nielsen (2013). Resilient, Receptive and Relevant: The African-American Consumer 2013 Report. Retrieved March 30, 2014, from http://www.nielsen.com/content/dam/corporate/us/en/reportsdownloads/2013\%20Reports/Nielsen-AfricanAmerican-Consumer-Report-Sept-2013.pdf

Park, C. W., \& Lessig, V. P. (1977). Students and Housewives: Differences in Susceptibility to Reference Group Influence. Journal of Consumer Research, 4(September), 102-110. http://dx.doi.org/10.1086/208685

Passel, J., \& Cohn, D. (2008). U.S. Population Projections: 2005-2050. Retrieved March 30, 2014, from http://www.pewhispanic.org/2008/02/11/us-population-projections-2005-2050

Seock, Y.-K., \& Bailey, L. R. (2009). Fashion promotions in the Hispanic market: Hispanic consumers' use of information sources in apparel shopping. International Journal of Retail and Distribution Management, 37(2), 161-181. http://dx.doi.org/10.1108/09590550910934290 
Shukla, P. (2011). Impact of interpersonal influences, brand origin and brand image on luxury purchase intentions: Measuring interfunctional interactions and a cross-national comparison. Journal of World Business 46(2), 242-252. http://dx.doi.org/10.1016/j.jwb.2010.11.002

Takooshian, H. (1987). Armenian immigration to the United States from the Middle-East. Journal of Armenian Studies, III (1-2), 133-155.

Talai, V. (1986). Social boundaries within and between ethnic groups: Armenians in London. Man, 251-270. http://dx.doi.org/10.2307/2803159

Wallendorf, M., \& Reilly, M. D. (1983). Ethnic Migration, Assimilation and Consumption. Journal of Consumer Research, 10(December), 292-302. http://dx.doi.org/10.1086/208968

Wilkes, R. E., \& Valencia, H. (1985). A Note on Generic Purchaser Generalizations and Subcultural Variations. Journal of Marketing, 49(Summer), 114-120. http://dx.doi.org/10.2307/1251621

\section{Copyrights}

Copyright for this article is retained by the author(s), with first publication rights granted to the journal.

This is an open-access article distributed under the terms and conditions of the Creative Commons Attribution license (http://creativecommons.org/licenses/by/3.0/). 